\title{
Anterior Tonsillar Pillar
}

National Cancer Institute

\section{Source}

National Cancer Institute. Anterior Tonsillar Pillar. NCI Thesaurus. Code C105762.

The anterior border of the tonsillar fossa. It is composed of the palatog lossus muscle. 